\title{
Registro sintético de uma vida: entrevista com Fábio Alves dos Santos Synthetic record of a life - Interview with Fábio Alves dos Santos
}

\author{
Fábio Alves dos Santos* \\ Entrevista realizada por Paulo Agostinho N. Baptista
}

\begin{abstract}
Resumo
Fábio Alves dos Santos (1954-2013) cursou Pedagogia, Ciências Sociais e Teologia, era Especialista em Filosofia da Religião (PUC Minas), Advogado (PUC Minas) e Mestre em Direito Constitucional (UFMG). Lecionou na PUC Minas como professor de Cultura Religiosa e depois como professor no Curso de Direito, atuando principalmente no Serviço de Assistência Judiciária - SAJ, especialmente cuidado de causas populares como as da ASMARE (Associação dos Catadores de Papel, Papelão e Material Reaproveitável de Belo Horizonte), da Pastoral de Rua, da Pastoral Carcerária, de movimentos de "Sem Casa", de ocupações e tantos outros grupos. Sua primeira publicação foi "Começo de mundo novo: sofrimento, luta e vitória dos posseiros de Santana dos Frades", Sergipe, numa versão popular em 1981 e outra pela Editora Vozes (1990). Fruto de sua dissertação de mestrado, Fábio publicou o livro "Direito Agrário: política fundiária no Brasil (1995). Em 2001 saiu seu último livro, uma coletânea de artigos publicados em diversos jornais: "Em defesa da vida". Num artigo em Horizonte (2004), juntamente com o advogado, amigo e colega Prof. Cristiano de Melo Bastos, discutiu "A prática jurídica na missão da PUC Minas". Fábio sofria de grave problema de visão há mais de 15 anos. Quase ficou cego depois de diversas cirurgias de miopia. Isso, porém, não o impedia de seguir seu constante compromisso com as lutas populares. Na última entrevista que concedeu, menos de um mês antes de sua morte (19 de outubro de 2013), depois de duro sofrimento de quase dois anos, no tratamento de um câncer no pâncreas, conta um pouco de sua vida, sua luta e sua percepção de várias realidades, especialmente da Igreja e da pastoral. Militante formado na Teologia da Libertação, de profunda espiritualidade, marcada por traços da religiosidade popular nordestina e comprometida com a libertação, Fábio Alves também buscou em sua vida abrir-se à teologia do pluralismo religioso, especialmente com o Santo Daime, em cuja tradição religiosa chegou a ser "fardado", mantendo uma profunda atitude espiritual aberta ao diálogo interreligioso.
\end{abstract}

Palavras-chave: Teologia da Libertação. Militância. Igreja Católica. Pastoral. Lutas populares. Diálogo inter-religioso.

Entrevista concedida em 23 de setembro de 2013 a Paulo Agostinho Nogueira Baptista. Fábio Alves dos Santos faleceu em 19 de outubro de 2013, em Belo Horizonte.

\footnotetext{
"Mestre em Direito Constitucional (UFMG) com a dissertação "Direito Agrário: política fundiária no Brasil” (1995), era Especialista em Filosofia da Religião e graduado em Pedagogia, Ciências Sociais e Teologia. Foi professor de Cultura Religiosa e de Direito na PUC Minas. País de origem: Brasil. E-mail: horizonte.pucminas@gmail.com.
}

Horizonte, Belo Horizonte, v. 11, n. 32, p. 1637-1649, out./dez. 2013 - ISSN 2175-5841 


\section{Entrevista}

Paulo Agostinho: Fábio, boa noite. Como se deu o processo de sua formação religiosa e depois a sua iniciação no cristianismo da libertação? Que pessoas foram importantes? Conte um pouco de sua história de vida.

FÁBIO - Nasci na cidade de Milagres, Ceará, na região do Cariri. Ali temos duas cidades de porte médio: Crato, sede da Diocese, e Juazeiro do Norte, terra do Pe. Cícero Romão Batista. Cresci em um ambiente extremamente religioso, onde as devoções católicas predominavam sobre as orientações doutrinárias do velho e conservador Pe. Joaquim Alves de Oliveira. A devoção à padroeira, Nossa Senhora dos Milagres, ao Pe. Cícero e aos santos impregnavam o cotidiano de todo o povo. Em casa, porém, estas práticas devocionais não eram tão fortes.

Ainda cedo comecei a estudar no colégio das Filhas de Santana. Freiras de origem italiana e muito conservadoras. Aos dez anos de idade vi acontecer o golpe militar de 1964 que contou com todo o apoio da Paróquia e das Filhas de Santana. O anticomunismo nos era pregado dia e noite.

Nascido em uma família de classe média, neto do Coronel Raimundo Alves que, por mais de vinte anos, foi o prefeito da cidade. Na família, os pobres estavam presentes como trabalhadores. Se, porém, mostravam-se irresignados com alguma coisa, eram tidos por preguiçosos ou revoltados. Contudo, se batiam à porta, rogando alguma esmola, sempre eram recebidos como objeto da caridade.

No colégio das freiras havia, igualmente, essa sensibilidade para uma caridade mais assistencialista aos pobres. Ainda aos dez anos, sob a orientação de Ir. Oswalda de Araújo, minha catequista, todos os sábados estava eu a ajudar, no colégio, a distribuir leite em pó, óleo, farinha de milho... que nos eram enviados pela Aliança para o Progresso, financiada pelos Estados Unidos. A semente de solidariedade aos pobres, porém, fora plantada com esmero.

Embora sem muita compreensão do fenômeno político da época, sempre me vi envolvido em assuntos da política. Minha casa era palco de reuniões com políticos e hospedava deputados e candidatos a cargos políticos vindo de Fortaleza, capital do Ceará.

Embora de uma família de treze filhos, tínhamos acesso a jornais e revistas semanais, como O Cruzeiro. Também recebíamos Seleções, órgão de divulgação ideológica dos Estados Unidos. A tônica sempre era o anticomunismo.

No colégio tínhamos acesso a uma biblioteca que nos permitia a leitura contínua de muitos e muitos livros. Em casa, dentre outras obras, tínhamos as obras completas de Jorge Amado que nos abriam para uma mentalidade mais crítica da organização social vigente na nossa terra. 
Aos quatorze ou quinze anos de idade comecei a tomar conhecimento dos livros produzidos por Dom Hélder Câmara, arcebispo de Olinda e Recife desde abril de 1964. Por incrível que pareça as obras de Dom Hélder ou sobre Dom Hélder me eram repassadas por Dona Letícia Lins, esposa de um chefe político da cidade e próspero industrial.

Em 1970 fui estudar no Juvenato Marista de Apipucos, no Recife, para dar início ao $2^{0}$ Grau de escolaridade. Ali comecei a ter acesso a todos os pronunciamentos de Dom Hélder que eram multiplicados pelo mimeógrafo, vez que nada do que ele falava podia ser reproduzido pela imprensa.

Em 1971 e 1972, enquanto estudava em escola pública ou privada, dava aulas para alunos pobres, cujas escolas eram mantidas pelos Irmãos Maristas. Havia um ambiente de solidariedade aos mais pobres, embora vivêssemos em casas de relativo conforto.

Os anos de 1972 e 1973 conheceram o início de um retrocesso na orientação dos Irmãos Maristas, cujo governo dava uma guinada para a direita. O Postulantado e o Noviciado foram feitos nesse ambiente de tensão.

Passei o ano de 1974 em Maceió, no Colégio Marista. Um ano perdido. Jovem cheio de ideais, ficava o dia inteiro a perambular pelos corredores do colégio, sem maiores compromissos profissionais ou intelectuais. Foi o preço pago por me ter insurgido contra a orientação ultraconservadora imprimida ao Escolasticado, no Recife.

Em 1975 retornei ao Recife, para o Colégio Marista. Iniciei o curso de Pedagogia e estreitei o contato com os trabalhos da Arquidiocese de Olinda e Recife e com os pronunciamentos de Dom Hélder. Animava-me a ação profética dos bispos do Nordeste, sobretudo a partir do documento "Eu Ouvi os Clamores do Meu povo", de 1973 .

Em fins de 1975 foi indeferido meu pedido de renovação dos votos na Província Marista do Brasil Norte. Pela intermediação do meu ex-mestre de noviços, fui para o Rio Grande do Sul, em Novo Hamburgo, onde me integrei a uma comunidade marista local. Trabalhava no colégio dirigido pelos Maristas e estudava Ciências Sociais na UNISINOS, dos Jesuítas, em São Leopoldo.

Os anos de 1976 e 1977 foram de intenso mergulho no trabalho pastoral com jovens trabalhadores e de aprofundamento em uma visão mais crítica da sociedade e da Igreja. Frequentar um Curso de Missiologia no Centro de Orientação Missionária, de Caxias do Sul, foi, para mim, privilegiado momento de fortalecer a opção pelos pobres. 
Em 1978 me encontrava em Propriá, Sergipe, fazendo comunidade com o Ir. Salatiel, ex-provincial Marista, e que vivia em certa diáspora no trabalho de professor e de presença junto aos pobres e aos jovens da Diocese. A Diocese de Propriá, dirigida por Dom José Brandão de Castro, contava com uma boa equipe pastoral, profundamente comprometida com as lutas do povo.

Eu trabalhava como professor em três escolas católicas da cidade. Nas horas livres, acompanhava os índios Xokó-Kariri, na vizinha Porto Real do Colégio, em Alagoas. Também os trabalhos com os jovens da cidade. Muito rapidamente me vi envolvido na luta dos posseiros de Santana dos Frades, em Pacatuba, Sergipe, luta esta que acompanhei até a vitória da desapropriação da terra no início dos anos 80.

Já em 1979 deixei a comunidade do Ir. Salatiel e comecei a partilhar a vida com Jean-Noel Barro e Nanou Deghilage, voluntários belgas profundamente engajados nos trabalhos sociais da Diocese de Propriá.

Conviver com uma Igreja pobre e comprometida com os pobres era a melhor escola que poderia encontrar. Uma equipe pastoral muito comprometida e um bispo com um senso de pastoreio que sempre me impulsionava para mergulhos mais profundos.

A partir de 1979 assumi a coordenação do Conselho Indigenista Missionário CIMI/Nordeste. Percorria os Estados da Bahia, Sergipe, Pernambuco, Alagoas e Paraíba, visitando as comunidades indígenas, as Dioceses, as Paróquias, as comunidades de freiras da região, as Universidades, as redações de jornais. Era intenso o trabalho de articulação dos índios entre si, dos agentes de pastoral da Igreja, dos estudantes e professores, e com a imprensa. Uma experiência mais que enriquecedora sob o ponto de vista humano, intelectual e espiritual.

Em 1983 e 1984 parei as atividades e fui para o Recife. Ali conclui o curso de Pedagogia e frequentei, por dois anos, o Curso de Teologia, no Instituto de Teologia do Recife, fundado por Dom Hélder Câmara e fechado, posteriormente, por seu sucessor.

Em 1985 vim para Belo Horizonte, onde me casei com a radialista Irma Reis, com quem tive dois filhos: Amílcar Reis Alves dos Santos e Cecília Reis Alves dos Santos. Ele, advogado. Ela, arquiteta e mestranda em Arquitetura, na UFMG.

De imediato iniciei o trabalho com os índios de Minas Gerais, vinculado ao CIMILeste. O acompanhamento da luta dos Xakriabá, em Missões, foi o mais intenso e mais conflitivo. O líder Rosalino e mais dois índios foram chacinados em fevereiro de 1987. O conflito se acirrou e as terras dos índios foram liberadas. A Diocese de Januária, através do bispo Anselmo Muller e dos padres alemães da Sagrada Família, tinha muita dificuldade de compreender o nosso trabalho e a luta dos índios. 
Em 1988 deixei o CIMI e passei a atuar junto aos sem-casa e aos presos, através da Pastoral de Direitos Humanos da Arquidiocese de Belo Horizonte e da Pastoral Carcerária. Posteriormente, junto à população em situação de rua, através da Pastoral de Rua. Em 1990 concluí o Curso de Direito, na PUC Minas, onde lecionava desde o ano de 1988. O curso de Direito me proporcionou maior efetividade no patrocínio das causas envolvendo os interesses dos pobres.

No início dos anos 2000 fui convidado pelo Ir. Afonso Murad, então provincial dos Maristas em Belo Horizonte, a elaborar um projeto de assistência aos jovens encarcerados. Imediatamente estabeleceu-se uma parceria entre Irmãos Maristas, PUC Minas e a Arquidiocese de Belo Horizonte, culminando na Constituição da Associação de Proteção e Assistência ao Condenado da Região Metropolitana de Belo Horizonte - APAC/RMBH. Tive, assim, a oportunidade, de presidir o Conselho de Fundadores da APAC e iniciar um longo debate em torno de referido projeto. Papel fundamental desempenhou o Cardeal Dom Serafim Fernandes de Araújo emprestando todo o apoio político ao projeto. Dom Raimundo Damasceno, então Secretário Geral da CNBB, facilitou-nos duas audiências para que o projeto arquitetônico da lavra do professor Flávio Agostini fosse apresentado ao Ministro da Justiça. Finalmente, depois de muitos embates com o Estado de Minas Gerais, foi inaugurada a APAC de Santa Luzia. A nova orientação dada à Arquidiocese de Belo Horizonte e à PUC Minas por seu novo Arcebispo e pelo novo Reitor, respectivamente, fizeram-me ver ser oportuno desligar-me do projeto com o qual me comprometi por longos e duros sete anos. Foi uma ruptura das mais dolorosas em minha vida.

Continuei mergulhado no patrocínio das causas de inteiras comunidades dos semcasa, através do Serviço de Assistência Judiciária da PUC Minas.

Paulo Agostinho: Você militou em defesa de índios, posseiros, camponeses, sem terra, população de rua, dos presos, como advogado de movimentos sem casa, de movimentos de ocupação e de tantos outros grupos. Num olhar retrospectivo e de autocrítica, o que deu certo e deveria continuar? $\mathrm{E}$ o que deveria ser feito de forma diferente? O que você mais aprendeu no seu trabalho com o povo e que poderia servir de referência para agentes de pastoral e militantes populares?

FÁBIO - Sob o ponto de vista da fé e da metodologia de trabalho, bem como de uma teologia comprometida com a causa dos mais pobres, guardo as muitas belas lições aprendidas ao longo da caminhada com os agentes de pastoral, do CIMI e das Pastorais Sociais. Guardo, ainda, o testemunho das comunidades religiosas inseridas nos meios populares, o mais belo rosto da Igreja comprometida com os pobres. Guardo as lições de bispos e teólogos da envergadura de Dom José Brandão de Castro, de Própria/SE; Dom Hélder Câmara, de Olinda e Recife/PE; Dom 
Tomás Balduíno, de Goiás Velho/GO; Dom José Maria Pires, de João Pessoa/PB; Dom José Rodrigues, de Juazeiro/BA; Dom Pedro Casaldáliga, de São Felix do Araguaia/MT; Padre Paulo Suess; Leonardo Boff; José Comblim; Pe. Oscar Beozzo, Frei Carlos Mesters, Ir. Ivone Gebara...

Década de 70 e década de 80 foram, para mim, tempos de grande florescimento da Igreja dos Pobres. Havia uma viva articulação dos organismos da Igreja em favor das lutas dos pobres: CPT, CIMI, Pastoral das Vilas e Favelas, CEBs... A formação seminarística era norteada para o serviço aos pobres. Havia preocupação com a formação bíblica dos membros das comunidades, cuja expressão maior era o CEBI.

Esta novidade toda, contudo, convivia com as velhas estruturas eclesiais e movimentos bem conservadores. Havia, poder-se-ia dizer, um pluralismo dentro da Igreja. Na Arquidiocese de Olinda e Recife, por exemplo, enquanto o Seminário Regional, o Instituto de Teologia, a Comissão Justiça e Paz, o Encontro de Irmãos, a Pastoral Rural e outras iniciativas de solidariedade aos pobres eram fortalecidas, convivia-se com boa parte do clero conservador e outros movimentos de Igreja não menos conservadores. O mesmo se diga na Arquidiocese de Belo Horizonte. Havia um pluralismo tensionado.

Na CNBB a realidade não era diversa. Direções, ao longo de vários mandatos, bastante progressistas em meio a um conjunto de bispos extremamente conservadores. É quando João Paulo II assume o pontificado e se começa longa, sofrida e lamentável marcha para o retrocesso. Tenta-se restaurar um modelo de Igreja piramidal, sustentado em uma teologia conservadora. A luta contra a Teologia da Libertação conhece forte impulso.

Evidentemente, é muito difícil e muito pobre dividir a igreja entre conservadores e progressistas porque a situação é muito mais complexa. O desafio é a convivência plural entre as correntes múltiplas da igreja, porque eu acho que o fato da igreja não ter fronteiras é que torna rica a experiência cristã das comunidades conforme o Espírito aponta.

Agora, sobre fracasso ou sucesso do trabalho pastoral que desenvolvi, é muito difícil ter uma conclusão clara sobre isso. O que vejo hoje, por exemplo, tendo presente a maneira como as ocupações urbanas em Belo Horizonte estão se conduzindo, que seria importante resgatar e enfatizar que os pobres são e devem ser sujeitos e protagonistas do seu processo de libertação.

Paulo Agostinho: E isso não está acontecendo?

FÁBIO - Eu acho que hoje não. Os movimentos sociais, ideologicamente organizados, e que apóiam, por exemplo, as ocupações, estão imprimindo uma tônica de muito diversionismo: não acatar decisões comunitárias tomadas relativamente à continuidade do processo de negociação, que era apoiado pela comunidade e que foi amplamente discutido e concluído como o caminho mais 
viável. Com a negativa disso, fruto de um projeto ideológico externo à comunidade, que se impôs à comunidade, não prevaleceu a vontade popular.

Paulo Agostinho: Comparando esse processo com a sua experiência pastoral em Santana dos Frades, lá foi diferente?

FÁBIO - Foi. Em Santana dos Frades eu atuava com uma igreja que estava lá, com a equipe missionária.

Paulo Agostinho: E o povo era e foi sujeito?

FÁBIO - O povo era sujeito porque tudo era decidido por eles. Nas reuniões com o governador, eles entravam no palácio e eu não. Nas reuniões com o secretário de segurança, eles entravam e eu não entrava. E eles foram tanto sujeitos que havia projetos distintos para o local. Terminado o processo de desapropriação veio a proposta da igreja de que os coqueiros de Santana dos Frades fossem mantidos coletivamente. Mas eles disseram não: "vamos dividir os coqueiros, mas não dividiremos a comunidade". Eles dividiram os coqueiros, dividiram a terra. Fizemos um processo atípico, que não conheço em outro local do Brasil. O INCRA fez a partilha e a distribuição dos lotes de tal modo que impediu que eles vendessem a terra para as pessoas de fora. Até hoje, desde 1980, eles continuam lá, as mesmas famílias donas dos lotes. Claro que os filhos não tiveram as condições de continuar lá porque os lotes eram mínimos, mas os lotes continuam lá. Infelizmente, o espírito comunitário não resistiu ao tempo, o individualismo predominou.

Paulo Agostinho: Em outros trabalhos pastorais você viu acontecer esse processo de se trabalhar a construção do sujeito e da cidadania, civil e eclesialmente, na perspectiva de Paulo Freire?

FÁBIO - Conheci muitas experiências nas quais tudo funcionava bem: a organização da comunidade, a luta, até a conquista dos objetivos, da meta imediata a que se perseguia. Depois, o individualismo predominava e as comunidades eram desfeitas. É com certa frustração que eu digo isso. Nas ocupações, muitas que acompanhei e patrocinei a causa jurídica em Belo Horizonte, ao longo do processo jurídico o trabalho era de fortalecimento da comunidade, de construção de senso comunitário para reunir o povo, para poder patrocinar encontros, festas, etc. Quando eu chegava lá e dava notícia que eles ganharam a causa na justiça, no dia seguinte essas comunidades já não se reuniam mais. 
Paulo Agostinho: Será que foi erro na preparação e/ou é também um problema mais profundo, que toca o aspecto antropológico e do nosso contexto de época: egoísmo, individualismo, falta de compromisso? O que você acha?

FÁBIO - Eu vejo que no meu trabalho houve a limitação quanto à promoção de uma formação cristã mais profunda. Ficávamos na prática devocional e na superfície do evangelho. Faltou a consolidação de um grupo verdadeiramente cristão, impregnado de uma boa formação cristã. Eu nunca tive a oportunidade de fazer isso em nenhuma comunidade que trabalhei, tanto com os índios quanto os posseiros e "sem casa". E aí, todas as vezes, por exemplo, quando os índios ganhavam a causa, reproduziam o mesmo modelo, o modelo político tradicional, as mesmas práticas políticas. Em Santana dos Frades, repetiam as políticas mais atrasadas. Algumas lideranças indígenas, os caciques, por exemplo, reproduziam o modelo do "coronel". É uma coisa impressionante, fazendo alianças com o poder.

Paulo Agostinho: A questão anterior, na verdade quis colocar um problema e um desafio para a pastoral: colocar o rótulo de "defesa do pobre" não resolve a situação pastoral ou é solução mágica para a libertação. O pobre, em maior medida, pela ampla carência que vive, expressa ainda mais as limitações humanas, com todas as suas contradições, inclusive, como Paulo freire dizia, introjetando o dominador.

FÁBIO - Sim, muitos introjetam dentro de si o opressor e, quando têm a oportunidade, reproduzem-no de maneira brilhante. São exímios alunos, reproduzem a ideologia do mestre e as práticas do mestre burguês de maneira muito contundente.

Paulo Agostinho: Não basta apaziguar a consciência com a afirmação que se luta pelos pobres. Importa é a qualidade do trabalho que efetivamente constrói sujeitos de seu processo de libertação.

FÁBIO - Sim. A única coisa que vi, depois de 30 anos, foi um movimento indígena, em 2011, de mulheres, de professores indígenas, os Capinauá, no estado de Pernambuco, muito interessante e muitíssimo promissor. Não tive possibilidade de aprofundar, mas parecia representar o fortalecimento do ideal comunitário indígena.

Paulo Agostinho: Mas foi fruto de trabalho pastoral mais profundo? 
FÁBIO - Talvez sementes que foram lançadas e que começaram a dar frutos e que me encantaram. Porém, noutra comunidade dos Capinauá havia desavenças muito fortes, muitas contradições e violência. A questão é que nós acreditávamos muito no ideal "os pobres são sujeitos e protagonistas da construção de um mundo novo". Mas esse é um processo a ser construído, trabalhado. Hoje, eu me pergunto: onde está o mundo renovado no final desse processo de luta? Olhando, em retrospectiva, houve sim muitas situações novas e avanços: pessoas morando em casas mais decentes, tendo sua terrininha para trabalhar, conquistando direitos... Isso é maravilhoso! Mas será que desse processo surgiram homens novos, mulheres novas? Receio que não. Talvez alguns.

Paulo Agostinho: É um desafio.

FÁBIO - Talvez soe pessimista dizer isso.

Paulo Agostinho: Penso que você é realista. Colocar a chancela "luta em defesa dos direitos" não garante que as pessoas consigam conviver dignamente com os direitos conquistados. Deu-se um passo. Há outros e muitos mais no processo de libertação, de renovação do ser humano, de construção da vida de comunidade, da capacidade de reconciliação, de perdão. Esses e muitos outos são ideais religiosos, são sonhos do cristianismo, particularmente.

FÁBIO - Há jovens de Santana dos Frades, filhos dos que conquistaram as terras, que têm outras terras hoje e lá estão piores do que seus pais em termos de relacionamentos. Há aqueles que partiram para o tráfico, para o furto. Quando outros jovens foram para a formação nas escolas agrícolas, até organizadas por movimentos sociais, e voltaram, se engajaram nos trabalhos da prefeitura com a mesma visão politiqueira da cidade. Eu não via nada de novo nesses técnicos, formados em bons movimentos sociais. Faltou algo.

Paulo Agostinho: Essa é uma critica interessante que merece ser refletida. Voltando à questão da Igreja, sabemos que sua estrutura sempre foi clerical e masculina, na quase totalidade de sua história. Na sua experiência, apesar do advento das CEBs a partir dos anos de 1970, que implicações essa estrutura trouxe para o trabalho pastoral?

FÁBIO - Em que pese o Concílio Vaticano II ter definido a Igreja como o povo de Deus, a sua organização ainda se assenta num modelo de Igreja episcopal e clerical. O protagonismo dos leigos e dos pobres, se bem que experimentado na 
base, tem, ainda, pouca relevância na estrutura maior da Igreja. Tanto é que, pouco a pouco, o desmonte começou a se dar a partir da substituição de bispos progressistas por bispos muito conservadores. Paradigmático é o que ocorreu com a sucessão de Dom Helder Câmara. Para Olinda e Recife foi enviado um obscuro carmelita, então bispo de Paracatu, Minas Gerais, cujo trabalho principal se caracterizou pelo desmonte do que fora construído no governo de Dom Helder. Até o Seminário Regional e o Instituto de Teologia foram fechados e abertos outros nos moldes tridentinos. Isto ocorreu Brasil afora. O resultado é o que estamos colhendo: uma Igreja eminentemente clerical e um clero acentuadamente medíocre, pois a qualidade da teologia ministrada nos Institutos de Teologia clama aos céus. Não sem razão os movimentos carismáticos, as novas comunidades e tantos outros do mesmo naipe encontraram terreno fértil para prosperarem. Claro que a chama da libertação não se apagou. Permaneceu nos subterrâneos a espera de um momento propício para reaparecer na luta dos pobres.

Vinte e até trinta anos depois me volto para aquelas comunidades de posseiros, índios, sem-casa com as quais caminhei e pelas quais dei o melhor de minha vida. Confesso que não fico tão entusiasmado com o que vejo. Registramos conquista no quesito moradia, recuperação de terra e manutenção na terra. Mas não vejo uma qualidade nova nas relações interpessoais. Como disse, uma vez conquistada a casa ou a terra, o individualismo prospera e o exercício do poder se manifesta tão velho quanto nos tempos do opressor a ser combatido. Mesmo na prática política cotidiana, as velhas raposas da política local se sentem muito à vontade com suas práticas clientelistas. $\mathrm{O}$ homem novo ou a mulher nova não parecem eclodir como resultado de tão sofrido processo. Comunidades cristãs não vicejam. Ao que tudo indica não ocorreu um verdadeiro processo de evangelização. Sobre tudo isto, gostaria muito de ver uma avaliação de pastoralistas, teólogos e sociólogos para compreender o que ocorre e o que ocorreu.

Mesmo me posicionando com este aparente pessimismo, acredito piamente que o Espírito continua soprando e o movimento rumo ao novo, ao bom e ao belo continua se processando. Nunca se retrocede ao ponto de partida, E novos passos adiante poderão ser dados.

Paulo Agostinho: Desde o Vaticano II houve grande incentivo ao diálogo ecumênico e inter-religioso na igreja católica. Como você pensa essa questão? Na sua vida e trabalho esse diálogo se fez presente?

FÁBIO - No campo do ecumenismo, o povo está sendo dividido pelas religiões. O pentecostalismo não favorece o encontro de irmãos de denominações diferentes. $\mathrm{O}$ fundamentalismo bíblico separa os cristãos e afasta os não-cristãos. Não é na pedagogia do encontro e do diálogo que se alimenta, mas na do confronto e do distanciamento. 
Nos últimos treze anos vivi uma experiência riquíssima no convívio com as comunidades do Santo Daime da Região Metropolitana de Belo Horizonte. Mais intensamente convivi com as comunidades de Santa Luzia e de Lagoa Santa. Delas recebi a melhor acolhida, sendo recebido, inclusive, como um "fardado". Com elas vivi fortes momentos de convívio fraterno. Delas me vieram gestos mil de solidariedade e ternura. A elas sou imensamente grato. Minha visão ecumênica se expandiu neste rico convívio. Imprescindível que se criem momentos de encontro, oração e reflexão de pessoas com opções religiosas distintas. Isto é possível e, quando ocorre, tem sido muito proveitoso. As Irmãzinhas de Jesus, em Belo Horizonte, estão acolhendo um grupo constituído com pessoas de diversas orientações religiosas, para retiros de carnaval. São momentos indizíveis de comunhão e partilha. Oxalá essa iniciativa se multiplicasse e prosperasse em outros ambientes das Igrejas.

Paulo Agostinho: É interessante que as vezes há preocupação com o ecumenismo e o dialogo inter- religioso com as outras religiões, mas esse diálogo não acontece no âmbito interno das igrejas e religiões.

FÁBIO - Dom Serafim dizia: "A arquidiocese não pode ser do meu tamanho, seria muito pobre". Acho essa postura de um pastor muito bonita, admite a possibilidade de outros pensarem diferente. Sinto eclodir no mundo uma espiritualidade, não necessariamente vinculada a alguma crença religiosa, uma espiritualidade da contemplação e da meditação, muitas vezes bebendo em fontes cristãs ou religiões orientais, e que esta espiritualidade está semeando no mundo pessoas novas, pessoas diferentes, e que contagiam seus ambientes. Vejo, por exemplo, aqui em Belo Horizonte, no Eremitério Nazaré da Serra, em Nova União, um lugar onde esses leigos que optaram pela busca de uma vida mais contemplativa ou meditativa, encontram uma fonte de reabastecimento e que transcende as religiões. Pessoas de diversas orientações para lá acorrem e são muito bem acolhidas e se sentem muito bem, embora no Eremitério a espiritualidade se traduza de uma forma cristã e até católica, mas com abertura tal que todos se sentem bem acolhidos.

Paulo Agostinho: Há grande expectativa da população por mudanças. Recentemente, tivemos a eleição do Papa Francisco. Quais as suas expectativas?

FÁBIO - No mundo inteiro e, particularmente no Brasil, se sente um desejo incontido por mudanças no campo da política e da economia. A hegemonia da ideologia liberal e as perversas consequências do capitalismo parecem não encontrar mais guarida nos corações da humanidade. As guerras ainda alimentadas em diversas regiões do mundo apenas denotam a iniquidade do sistema capitalista 
e apontam em direção à imperiosa necessidade de mudanças. O Espírito, pois, não está dormindo. Está suscitando na história um novo movimento.

Em termos de Igreja, não se pode deixar de registrar o que de surpreendente há na eleição do Papa Francisco. Surpreendente, igualmente, foi o belo gesto de renúncia de Bento XVI. O que de tudo isso poderá resultar, estou certo, serão muitos ganhos para a grandiosa missão da Igreja de ser presença amorosa do Pai no mundo, sobretudo junto aos mais necessitados.

Paulo Agostinho: Fábio, como você tem vivido esses últimos meses com seu problema de saúde? Como nessa experiência sua espiritualidade o tem ajudado a enfrentar esse sofrimento? Que mensagem você deixa com esse "registro sintético de uma vida"?

FÁBIO - Há quase dois anos venho enfrentando os desafios que me são postos por um câncer de pâncreas. Quanta novidade me ocorreu neste sofrido tempo. A primeira novidade é o sentimento de ser cuidado por tantos e tantas. Familiares de perto e de longe não mediram esforços para me ajudarem na busca da cura. Vinham de longe e aqui passavam dias em inteira dedicação. Eram verdadeiros Cireneus. Não podem avaliar o que isto significou no meu coração e no meu tratamento. Mas Deus sabe.

Os amigos foram uma preciosidade. De matizes religiosos os mais diversos. De opções políticas as mais variadas. De origem social plural. Foram presenças constantes. Eram os meus melhores medicamentos. Como pude compreender o incomensurável valor de Mateus, no capítulo 25, quando Jesus destaca a importância de se cuidar dos mais necessitados. "Eu estava doente e cuidaste de mim". Nada mais humanizante para quem cuida, como para quem é cuidado. Eterna será a minha gratidão.

Nesse registro, deixo a memória como se passaram meus 59 anos de vida. Sinto que esta etapa de vida terrena se aproxima do fim. E como é difícil que alguns dos meus mais próximos admitam esta possibilidade. Todos gostaríamos que outro fosse o desfecho. Mas os amorosos desígnios de Deus são outros. Desde menino minha mãe repetia o que Santa Paula Fransinetti dizia: "Vontade de Deus tu és meu paraíso".

Com o apóstolo Paulo gostaria de dizer que combati o bom combate. Terminei minha carreira. Guardei a fé. 
Claro que muitos erros cometi ao longo de tantos anos. Muitas pessoas magoei, mesmo que involuntariamente. A todos peço perdão e misericórdia.

Confio-me à prece de todos e de todas. Rogo a proteção da Boa Mãe. Abandono-me nas mãos misericordiosas do Pai.

\section{Publicações de Fábio Alves dos Santos}

SANTOS, Fábio Alves dos. Começo de mundo novo: sofrimento, luta e vitória dos posseiros de Santana dos Frades. Propriá: Secretariado Arquidiocesano de Pastoral/Diocese de Propriá, 1981.

SANTOS, Fábio Alves dos. Começo de mundo novo: sofrimento, luta e vitória dos posseiros de Santana dos Frades (Sergipe). Petrópolis: Vozes, 1990.

SANTOS, Fábio Alves dos. Direito agrário: política fundiária no Brasil. Belo Horizonte: Del Rey, 1995.

SANTOS, Fábio Alves dos. Em defesa da vida. Belo Horizonte: O Lutador, 2001.

BASTOS, Cristiano de Melo; SANTOS, Fábio Alves dos. A prática jurídica na missão da PUC Minas. HORIZONTE, Belo Horizonte, v. 3, n. 5, p. 82-100, mai. 2009. Disponível em:

<http://periodicos.pucminas.br/index.php/horizonte/article/view/565/597>. Acesso em: 17 Dez. 2013. 